\title{
DECUBITUS ULCER OF THE HEEL. REPORT OF TWO CASES REQUIRING PARTIAL RESECTION OF THE OS CALCIS
}

\author{
By ERnest Bors, M.D., D.A.B., F.A.C.S. \\ From the Spinal Cord Injury Service of the Veterans Administration Hospital, Long Beach, \\ California, and the Department of Surgery, University of California School of Medicine, \\ Los Angeles, California, U.S.A.
}

THE historical development of decubitus ulcer therapy has been reported elsewhere (Bors, I948), starting with excision of a scar, the first repair of an active ulcer (Lamon \& Alexander, I945), the use of reconstructive methods with grafts and various types of flaps and finally the principle of ostectomy with either linear or flap closure. The literature is replete with reports on prevention, conservative and operative management of decubitus ulcer in general, and this field has been recently reviewed by Comarr (1958, I959). We shall confine our report to the management of heel ulcers in two particular cases.

Decubitus ulcer of the heel poses rarely a therapeutic problem in patients with spinal cord injuries. Its incidence among other ulcers has been reported as 8 per cent. (Conway \& Griffith, 1956), I8 per cent. (Yeoman \& Hardy, I954) and I9 per cent. (Conway et al., I947). We observed an incidence of 9 per cent. of heel ulcers. They 'frequently heal spontaneously' (Gelb, I952); some require transplantation of split thickness epidermis, used either as an onlay graft (Gelb, I952) or as a buried graft (Bors \& Comarr, I948; Walsh, I954) in order to expedite wound healing. Rarely has excision become necessary which includes the ulcer and parts of the os calcis. Cannon et al. (1950) reported seven cases of this type, and one case was described by Conway and Griffith (1956) which needed this procedure among a series of 45 heel ulcers. Wiltse et al. (1959) have reported seven patients who were treated with resection of the calcaneus but only one of these had traumatic paraplegia; four had osteomyelitis, one diabetes and one a leg fracture. We have been forced to use this technique in three heel ulcers of two patients among the many hundreds of ulcers seen during a period of approximately I 8 years. One of these patients had tetraplegia; the other had a low lesion which permitted him to walk without brace or cane.

\section{CASE PRESENTATION}

Case I. R. McC., at the age of 19 years, was injured in a diving accident on 4 Juiy I 957 and sustained a fracture dislocation; the last examination on 5 June I 962 showed a complete motor lesion below C6 and a dermatome level at C8 (light touch: C6, vibration: $\mathrm{C} 8$, position: thumb, index, middle finger, pinprick: $\mathrm{C}_{7}$ ), spoon test level of skin moisture: T9 left and T8 right, intercostal pressure perceived but less than abdominal pressure, abdominal pressure correctly localised above a line corresponding to the TI I dermatome but not below.

He underwent a tracheostomy on 5 July I957, a laminectomy on 7 July I957 with Blackburn skull tongs in place which were removed on 16 August 1957. The tracheotomy tube was removed on 27 September 1957. The date of an early suprapubic cystostomy is not known but he still carries the cystotomy tube.

A sacral decubitus ulcer was successfully closed on 27 January 1958. Buried epidermis grafts to the heels were applied on 23 November I 959 and again on I 2 February 1960. A subarachnoid alcohol block was done on 25 June 1959 because of automatic 
dyreflexia with epileptic seizure and subsequent pathological electroencephalographic tracing. A litholapaxy was done on 3 March 1959. Discharged on I2 July I960.

First readmission on 27 July 1960. Recurrence of the heel ulcers was treated with debridement (22 August 1960), brine bath, exposure to air and additional cleansing with peroxide and a third attempt at buried epidermis graft was done on I9 September I 960 . A fourth attempt with the same procedure was done on I March I96I. Discharged on 2 May I96I.

Second readmission on I8 May I96I because of upper respiratory infection, a superficial trochanteric ulcer and recurrent heel ulcers. On 28 July I96I a bilateral achillotenotomy was done in the hope that this would release some of the tension at the heels. Discharged on 28 July I96I.

Third readmission i 8 September I $96 \mathrm{I}$ because of recurrence of ulcers. On 2 October 196I the left ulcer plus part of the os calcis was excised. The wound was closed with stainless steel sutures over a drain, and on 17 January the same operation was performed on the right side (figs. I and 2). The histopathological diagnosis was hyperkeratosis and parakeratosis of decubitus ulcer without bone involvement. Discharged on 27 February 1962. The heels have remained well since the last surgical intervention.

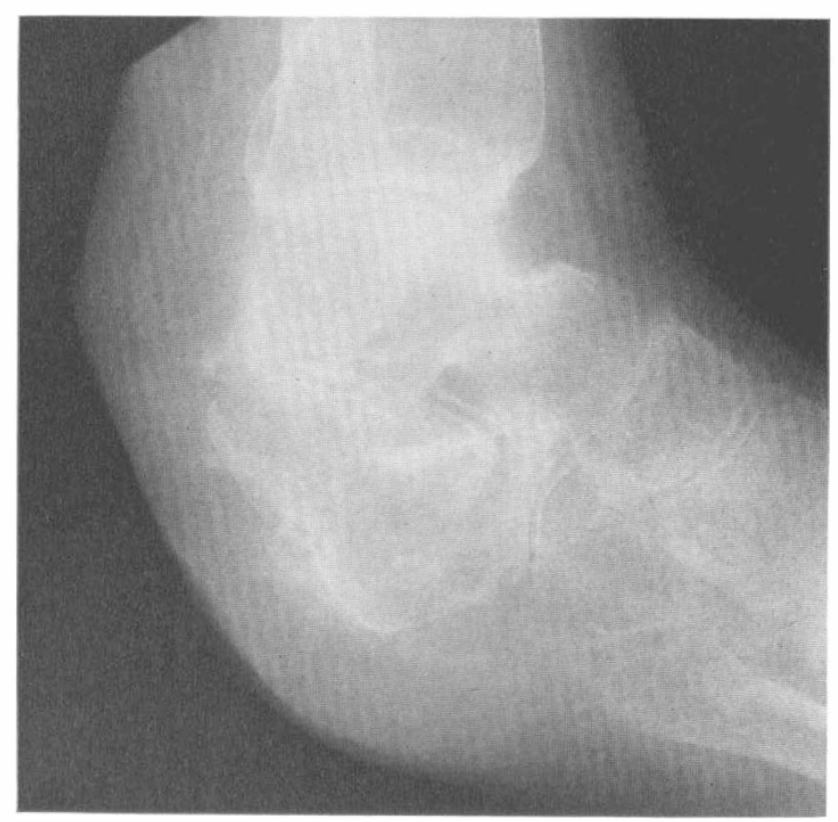

FIG. I

R. McC., 24 years, injury 4 July 1957, C6-7, incomplete. Radiographic appearance of the left calcaneus, eight months after resection.

Case 2. B. McC., at the age of 33 years, was injured in an airplane crash on 4 July I 949 and sustained a fracture of $\mathrm{L}_{I}$ and multiple rib fractures, fractures of the right clavicle, left first and second metatarsus and a cerebral concussion. A laminectomy on 7 July I 949 disclosed a 'swollen' cord and cauda equina.

At the time of the last examination on 29 May I962 his neurological status was as follows: micturition: fullness, no desire to void, facilitation by strain, passive inhibition, no sensation of urine passing; defaecation: no desire to defaecate, no sensation of stool 


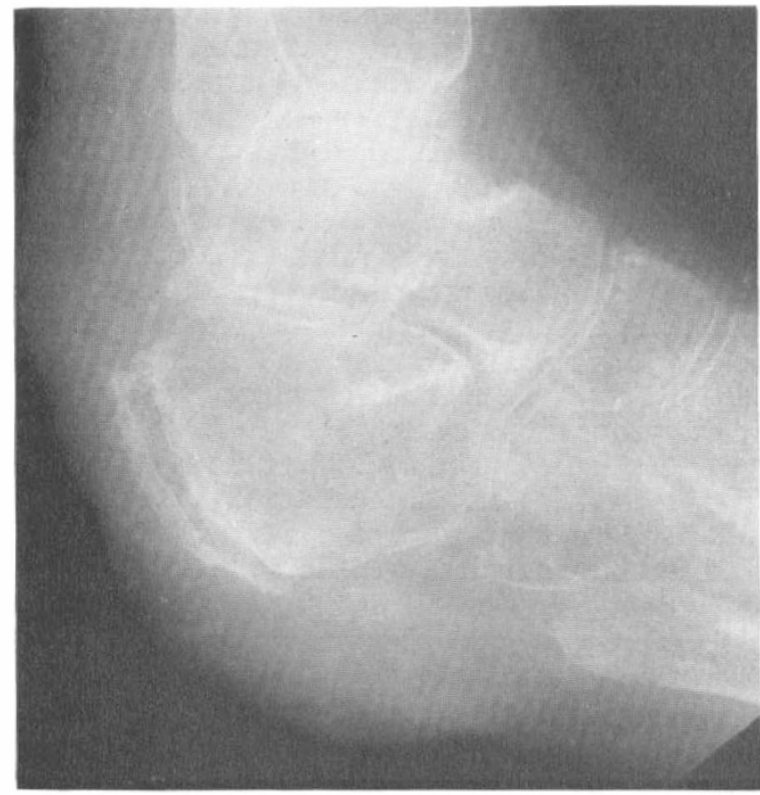

FIG. 2

R. McC., 24 years, injury 4 July 1957, C6, 7, incomplete. Radiographic appearance of the right calcaneus five months after resection; note newly formed calcification.

passing; erection: psychogenic, not reflex, trend to premature ejaculation, but orgasm frequently almost normal. Hypalgesia: in SI left and right, analgesia: below S2 left and right, and in L5 right. Anaesthesia: below L4 left, hypesthesia: in L5, SI right, and anaesthesia: below SI right. Pallanaesthesia (skin): below S2 left, pallhypesthesia: in L4, SI right, pallanaesthesia: in L5, and below SI right. Kinesthetic sense intact in left toes, absent in right toes 3-5. Motor function almost normal in hip and knees, left leg somewhat weaker than the right; 50 per cent. loss of left ankle movements and 30 per cent. loss of right ankle movements. Absence of ankle reflexes; absence of anal sphincter tone and bulbocavernosus reflex.

Discharged 4 April I950; bladder function returned within four months, sexual function within five months; walking with slight right limp but without brace or cane.

First readmission on 20 December 1950 for follow-up examination.

Second readmission on 20 March I95I for examinaticn following a fall.

Third readmission (to the Spinal Cord Injury Center of the V.A. Hospital, Hines, Illinois) on 6 April 1953. Left nephrectomy done there for pyelonephritis on 22 April 1953.

Fourth readmission on Io August 1953 because of left ureteral stump empyema; left ureterectomy done here on 9 September 1953.

Fifth readmission on I I January I954 for follow-up examination.

Sixth readmission on I2 April I 954 for swelling of the right leg, lymphangitis and first appearance of right heel ulcer, all of which subsided with conservative therapy.

Seventh readmission on 3I October 1954 because of fever caused by high residual urine; cured conservatively.

Eighth readmission on 25 January 1955 for left epididymitis which subsided with conservative therapy.

Ninth readmission on I 8 September 1955 because of injury of left foot in a swimming 
pool with infection, lymphangitis and lymphadenitis, all of which cleared up with conservative therapy.

Tenth readmission on I I March I956 for follow-up examination.

Eleventh readmission on 26 March 1956 for recurrent left epididymitis, which subsided with conservative therapy; first blood pressure elevation I40/90.

Twelfth readmission on 23 August 1956 for left epididymitis and first recurrence of ulcer right heel. Blood pressure IIo/80-90. Conservative therapy.

Thirteenth readmission on 7 January 1957 for second recurrence of right heel ulcer, $I \mathrm{~cm}$. in diameter, dry. Blood pressure 130/60. Conservative therapy.

Fourteenth readmission on 26 May 1958 for recurrence ( $3 \mathrm{rd}$ ) of right heel ulcer. The ulcer was similar in appearance to a mal perforant $d u$ pied. It was surrounded by mild hyperkeratosis. The blood pressure fluctuated from $125 / 80$ to $185 / \mathrm{I} I 0$ with an average of 160/100. Excision of the ulcer was done on 17 June 1958 in order to achieve better granulation. The patient had a homologous serum hepatitis in August I958 which

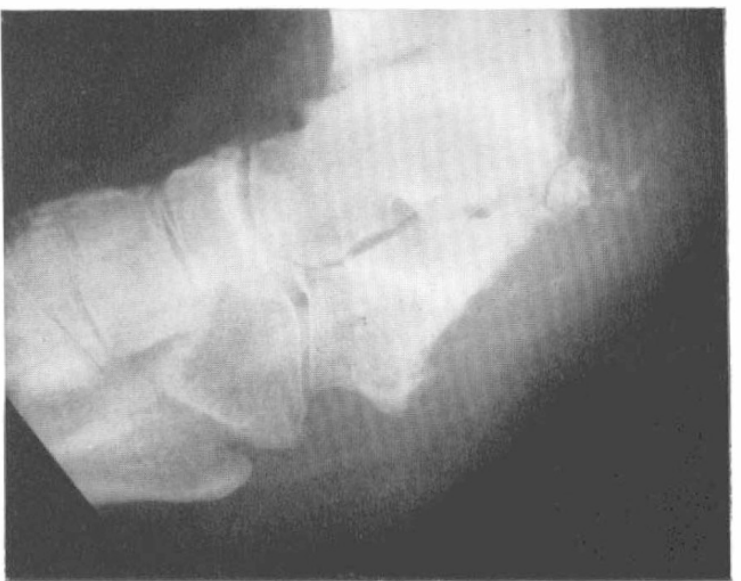

FIG. 3

B. McC., 45 years, injury 4 July I 949, LI, incomplete. Radiographic appearance of the right calcaneus 7 weeks after resection; os trigonum has been left intact. delayed further action. On I7 February 1959 a transurethral resection of the vesical neck was performed and restored the lost balance of bladder function. On 4 March I959 the ulcer was again revised, and good granulation resulted. On I May 1959 a flap was raised and sutured back to its bed in the left thigh. It was sutured to the ulcer on 29 May I958. Incision of the pedicle was done on 29 June 1959 and severance on 6 July I959. The donor site was grafted with buried epidermis on I3 July I959. A haemorrhoidectomy was done on 2I August 1959. One flap edge was revised on II January I 960 and thereafter the patient was fitted with an orthopaedic shoe.

Fifteenth readmission on 4 October 1960 for marginal breakdown of the graft. It healed by conservative therapy of brine bath and exposure to air. Blood pressure fluctuations from $120 / 80$ to $160 / 100$.

Sixteenth readmission on 25 January 1962 for recurrent breakdown of the graft, 50 per cent. of which was destroyed. The ulcer was thickwalled with hyperkeratotic margins, a deep crater and infected base. Pre-operative preparation with exposure to air and brine bath. On I4 March 1962 the ulcer was widely excised and two-thirds of the os calcis were resected (figs. 3 and 4). The wound was closed without drain by a few coapting stainless steel sutures. The histopathological diagnosis was decubitus ulcer showing pseudo-epitheliomatous hyperplasia without bone involvement. After removal of the sutures an Unna boot was applied from 2 April to 7 May 1962, and a prosthetic lift was constructed (fig. 5). His fluctuating blood pressure elevation (I30/90 to $190 /$ I20) was treated with Apresoline and later with Ismellin. The patient walks well even without the prosthetic lift.

\section{COMMENTS}

These two cases are representative of two different groups of ulcers: one, the rather frequent superficial, large ulcer of the quadriplegic, the other, a rare 


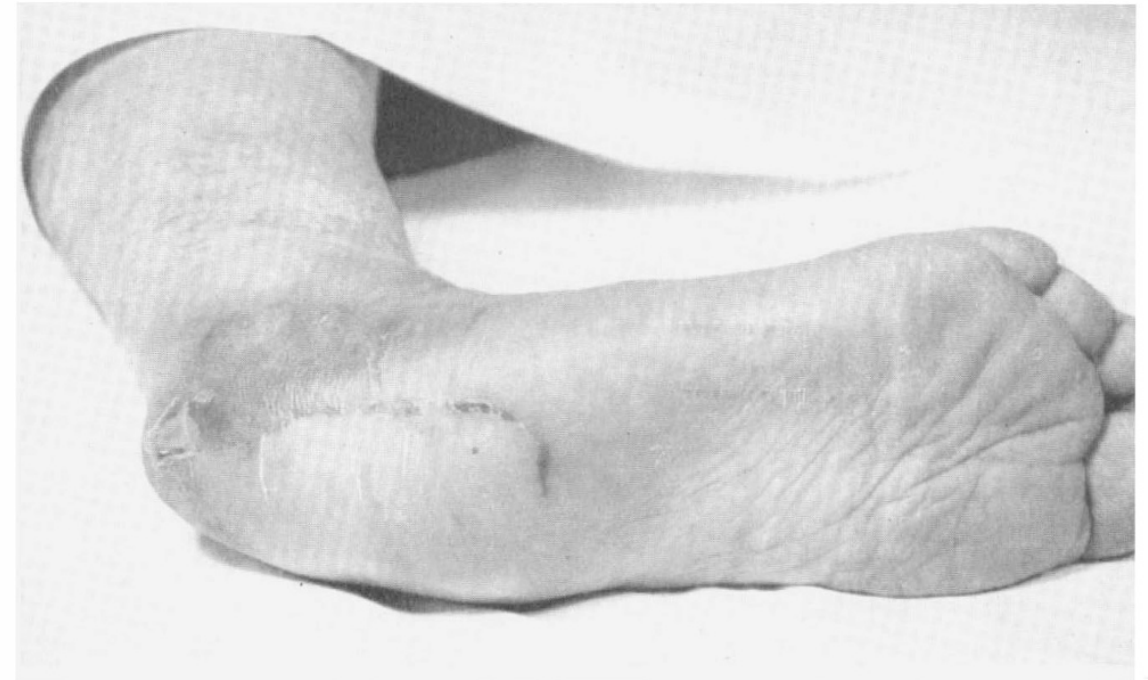

FIG. 4

B. McC., 45 years, injury 4 July 1949, LI, incomplete. Appearance of scar nine weeks after operation.

deep, tropic appearing ulcer of the patient with a conus and cauda equina lesion reminding of a mal perforant du pied. Both ulcers failed to stay closed following repeated grafting with buried epidermis seeds (Bors \& Comarr, I948a), and one

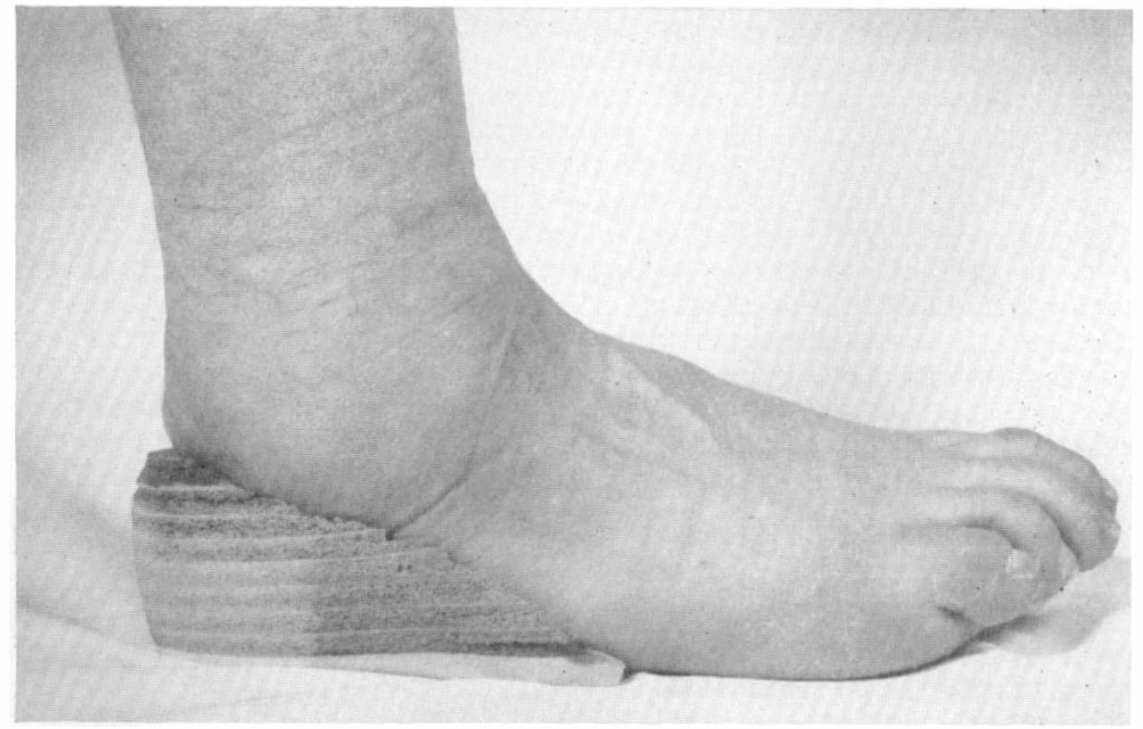

FIG. 5

B. McC., 45 years, injury 4 July I959, LI, incomplete. Prosthetic lift fitted to the defect of the heel. 
even following a cross-leg flap procedure; in that respect the latter case is similar to the patient (Case 3) of Wiltse et al. (I959), but their patient had only a peripheral sensory nerve lesion in association with a leg fracture.

Based upon the presented observations and those of the literature, it would seem logical that not more than two attempts should be made at grafting buried epidermis; if they fail, a more radical procedure with ostectomy will be indicated. Removal of bone has been recommended long ago for other locations (Bors \& Comarr, I948b), and 'it is futile to rotate a flap over a bony prominence' (Blocksma et al. 1949). Flap procedures of any sort seem to be more suited for the repair of traumatic lacerations of the heel (Lexer, I93I; Schmid, I958) than of decubitus ulcers at that site unless ostectomy is also performed (Cannon et al., 1950). However, it should be stressed that such heel ulcers which do not close spontaneously or with the aid of epidermis grafts are in our experience the great exception, and may occur about one in five hundred cases or even less frequently.

The operative technique of resecting the calcaneus is simple (Wiltse et al., 1959); it differs from Pridie's (I946) operation which removed the entire os calcis because of comminuted fractures in 15 patients. Wide skin excision of ulcers is always advisable because of the hyperkeratosis which carries the-admittedly low-potential danger of neoplasia; we observed the latter only once in the past I6 years in a sacral ulcer of Io years standing, which has been cured for the past I4 years following a V-Y closure. Once the heel ulcer is excised, the incision should be carried laterally; however, the ideal lateral approach of Wiltse et al. (1959), which was designed for the treatment of osteomyelitis of the os calcis, is not possible. We agree with these authors that the subastragalar and calcaneocuboidal joints should not be opened.

Contrary to Pridie (I946) and Wiltse et al. (1959) we have made no attempt in Case 2 to preserve the continuity of the Achilles tendon and plantar fascia without untoward effect; the patient retained the same reduced range of active movement postoperatively which he had pre-operatively; had he been able to tiptoe pre-operatively, suturing the Achilles tendon to the plantar fascia may have been advisable (Wiltse et al., I959). The wounds of both our patients healed well, in one with drainage, in the other without it. Loose approximation of the wound with stainless steel sutures was done in both instances and the sutures were left in place for three weeks. No plaster casts were used. However, the application of an Unna boot (Zincgelatine bandage) seemed beneficial for four weeks following the removal of the sutures. This period may even be prolonged where weight bearing is expected. Thereafter, a protective elastic bandage may be worn after the skin has been dusted with talcum powder. Only then is the prosthetic lift applied.

Continuous bath therapy (Jelinek, I953) and especially the brine bath (Nyquist, I959) are important adjuncts in the preventative, conservative and preoperative management of pressure sores. The latter has been used routinely at this Spinal Cord Injury Centre for more than I6 years.

After many failures to cure a decubitus ulcer, the discouragement of the patient who demands amputation of the limb is understandable. This was the experience of Wiltse et al. (1959) in their patient (Case 3), and it was also the case in our two patients. Resection of the calcaneus is a safe method to prevent amputation and eventually the patients are well satisfied that their request has not been granted. 


\section{SUMMARY}

I. The cases of two patients with decubitus ulcers at the heels are reported; these required resection of the os calcis in addition to the excision of the ulcers because repeated buried epidermis grafts and, in one patient, also a cross-leg flap procedure failed.

2. Decubitus ulcers of the heel which require this operation are very rare; it becomes indicated when two attempts at grafting buried epidermis fail to produce a permanent cure.

3. The two cases are discussed in the light of the pertinent literature.

\section{RÉSUMÉ}

L'auteur rapporte le cas de deux malades avec des escarres du talon; leur gravité necessita la resection du calcaneum, en plus de l'excision des escarres, parceque toutes les tentatives de greffe, et chez un malade une tentative de plastie par lambeau croisé avaient echouées.

Les escarres du talon qui requierent ce traitement sont rare, cependent celui-ci se trouve indiqué quand deux tentatives de greffe par enfouissement de l'épiderme echouent.

Les deux cas ont été discutés à la lumiere de la litterature competente.

\section{ZUSAMMENFASSUNG}

Zwei Patienten mit Dekubitalgeschwüren and en Fersen werden beschrieben, in denen Resektion des Os calcis notwendig wurde, machdem Hauttransplantate verschiedener Art sich als nutzlos erwiesen.

Dekubitalgeschwüre an der Ferse, welche diese Operation benötigen, sind sehr selten. Sie sind indiciert, wenn zwei Versuche, sie mit Hanttransplantaten zu heilen, erfolglos waren.

Die beiden Fälle werden im Lichte der einschlägigen Literatur discutiert.

\section{REFERENCES}

Blocksma, R., Kostrubala, J. G., \& Greeley, P. M. (1949). Plast. reconstr. Surg., 4, I23. Bors, E. (1948). Veterans Adm. techn. Bull. TB., I0, 503.

Bors, E., \& Comarr, A. E. (1948a). Surg. Gynec. Obstet., 87, 68.

BORs, E., \& COMARR, A. E. (I948b). Surgery, 24, 680.

Cannon, B., O’Leary, J. J., O’Neil, W., \& Steinsieck, R. (1950). Ann. Surg., 132, 760.

Comarr, A. E. (1958). F. Indian med. Prof., 5, 2307, 2354, 2379, 24I I, 2464.

Comarr, A. E. (I959). F. Indian med. Prof., 5, 2498, 2569, 2570, 2566.

Conway, H., \& GRIfFith, B. H. (I956). Amer. F. Surg., 91, 946.

Conway, H., Kraissl, C. J., Clifford, R. H., Gelb, J., Joseph, J. M., \& Leveridge, L. L. (1947). Surg. Gynec. Obstet., 85, 32 I.

GeLb, J. (1952). Plast. reconstr. Surg., 9, 525.

JELINEK, R. (1953). Int. F. Surg., 20, I56.

Lamon, J. D., \& Alexander, E. (1945). F. Amer. med. Ass., 127, 396.

LeXer, E. (I93 I). Die Gesamte Wiederherstellungschirurgie, vol. I., p. 228. Leipzig: Barth.

NYQUist, R. H. (1959). F. Amer. med. Ass., r69, 927.

PRIDIE, K. W. (I946). Surg. Gynec. Obstet., 82, 67 I.

Schmid, M. A. (1958). Arch. klin. Chir., 228, 256.

Walsh, J. J. (1954). Proc. R. Soc. Med., 47, i I 16.

Wiltse, L. L., Bateman, G., \& Kase, S. (1959). Clin. Orthop., 13, 27 I.

Yeoman, M. P., \& Hardy, A. G. (1954). Brit. F. plast. Surg., 7, I79. 